\title{
A sustentabilidade na Serra do Mar do estado do Paraná: uma avaliação de programas governamentais e não governamentais
}

\section{The sustainability of the Serra do Mar in the state of Paraná: an evaluation of governmental and non-governmenal programmes}

Edson Struminski

Universidade Estadual de Ponta Grossa

Resumo: Neste artigo estão sendo avaliados dois programas governamentais e um não governamental, que por sua natureza procuram propor políticas públicas para a Serra do Mar paranaense, área onde se encontram os principais remanescentes de biodiversidade do estado do Paraná. Trata-se feita uma análise discursiva dos programas, tendo em vista os parâmetros de sustentabilidade defendidos por cada um deles. Os discursos, nos quais os projetos estão embutidos, são o cartesianismo, o naturalismo, o liberalismo e o positivismo.

Palavras-chave: Serra do Mar. Programas de sustentabilidade. Análise discursiva.

\begin{abstract}
In this article, two governmental and one non-governmental programme are evaluated, which are proposing public policies for the Serra do Mar of Parana state, a region where the highest index of biodiversity in the state can be found. The programmes are analyzed on the basis of a discursive analysis that identifies the parameters of sustainability that are defended in each of them. The discourses into which the programmes are embedded refer to cartesianism, naturalism, liberalism and positivism.
\end{abstract}

Keywords: Serra do Mar. Sustainability programs. Discursive analysis. 


\section{INTRODUÇÃO}

Este artigo discorre sobre um tema bastante comentado, mas pouco aprofundado: a sustentabilidade. Quando observamos os discursos de políticos, empresários e representantes de instituições não governamentais, percebemos que a mensagem que se pretende passar sobre a sustentabilidade revela-se, quase sempre, simplista. Entretanto, quando refletimos com mais atenção sobre esse tema e, principalmente, quando temos a oportunidade de comparar diferentes concepções sobre a sustentabilidade em uma mesma área geográfica - como é o caso, por exemplo, da Serra do Mar paranaense -, percebemos que a sustentabilidade é um processo complexo que abriga diferentes discursos que envolvem a relação entre sociedade e natureza, podendo se completar ou mesmo se confrontar.

O objetivo deste artigo é, portanto, aproveitar a coincidência da ocorrência simultânea de vários projetos em uma mesma área geográfica em períodos recentes para evidenciar as diferentes concepções sobre sustentabilidade. Para que esse objetivo seja atendido, será feito um exercício hermenêutico de como os diversos discursos históricos sobre a sustentabilidade surgiram. Com isso, pretende-se estimular a reflexão sobre esse tema de vital importância para a sociedade.

\section{A ANÁLISE DE DISCURSO COMO MÉTODO DE TRABALHO}

A análise discursiva como um método científico é proposta por Foucault (1997, p. 11) como uma sistemática que não é do tipo lógico, nem do tipo linguístico. Caracterizase pelo recorte de um campo de projetos e pela definição de uma perspectiva legítima para o sujeito de conhecimento. Também podemos definir a análise do discurso pela fixação de normas para a elaboração de conceitos e teorias. Cada uma delas supõe um jogo de prescrições que determinam exclusões e escolhas.

Os discursos, nesse caso, impõem aos indivíduos certas regras e assim não permitem que todos tenham acesso a eles. (FOUCAULT, 2004, p. 37). Criam-se, assim, as sociedades de discurso, cuja função é conservar ou produzir discursos, mas para fazê-los circular em um espaço fechado. (Ibidem, p. 39).

Para Foucault (1997, p. 11) as práticas discursivas não são pura e simplesmente modos de fabricação de discursos. Elas ganham corpo em conjuntos técnicos, instituições, esquemas de comportamento, tipos de transmissão e de difusão, em formas pedagógicas, que ao mesmo tempo as impõem e mantêm.

Dessa forma, segundo Araújo (2001, p. 64), Foucault considera que há poder político, social econômico e institucional nas práticas discursivas. Assim, a análise desses discursos revela essa vontade de poder. O discurso não é simplesmente aquilo que traduz as lutas ou os sistemas de dominação, mas aquilo por que e pelo que se luta, o poder do qual se quer apoderar. (FOUCAULT, 2004, p. 10). Os discursos científicos, por exemplo, podem ser objeto de uma prática política e até mesmo depender dessa prática.

Assim, para Foucault (Ibidem, p. 8), em toda sociedade a produção do discurso é ao mesmo tempo controlada, selecionada, organizada e redistribuída por certo número de procedimentos que tem por função conjurar seus poderes e perigos, dominar os acontecimentos aleatórios, esquivar sua pesada e temível materialidade.

Finalmente, para justificar a análise dos discursos em ambientes investigativos que utilizem métodos interdisciplinares, pode-se chamar uma última vez Foucault 
(1997, p.11), que considerava que a prática discursiva não coincide necessariamente com obras individuais - mesmo que se manifeste ou apareça pela primeira vez através delas - e também não coincide obrigatoriamente com o que se costuma chamar ciências ou disciplinas, por mais que às vezes suas delimitações possam ser as mesmas. Para esse autor, uma prática discursiva pode reunir diversas disciplinas ou ciências, de onde se pode deduzir que sua análise deve ser, portanto, interdisciplinar.

As atuais relações entre sociedade e natureza refletem doutrinas e sistemas filosóficos que começaram a se difundir pelo mundo. A partir do período do Iluminismo, sobretudo, influenciaram, em maior ou menor grau, o pensamento político brasileiro e a própria sociedade brasileira como um todo. Essas diferentes doutrinas trouxeram consigo discursos que se materializaram, ao longo dos séculos, em variadas intervenções na natureza com resultados visíveis, até hoje, no mundo material.

Assim, foram identificadas e analisadas algumas doutrinas, cujos discursos serão apreciados neste trabalho: o racionalismo derivado do cartesianismo, fruto do pensamento iluminista (visto aqui como uma doutrina que visava à apropriação, à otimização e ao aproveitamento racional dos recursos naturais); o naturalismo, como uma doutrina de reação aos excessos utilitaristas desse cartesianismo e dono de uma visão particular e romântica da natureza; o liberalismo como doutrina política que fundamentou a criação do Estado nacional brasileiro, fortaleceu os anseios de liberdade e de uso privado da natureza de sua elite e gerou uma variante social; e o positivismo, como uma doutrina científica que fundamentou a República no Brasil e o intervencionismo estatal sobre o meio natural e sobre a sociedade.
Como área de estudo empírico foi considerada a Serra do Mar paranaense e alguns programas ou projetos que se propõem a executar esses discursos na região. Recensões críticas sobre esses projetos foram realizadas com o intuito de comprovar se a hipótese da sustentabilidade é válida para os mesmos.

\section{OS DISCURSOS SOBRE A SUSTENTABILIDADE}

\subsection{O discurso cartesiano}

Segundo Foucault, a partir do século XVI surgiram novos e diversos discursos que hoje entendemos como formas da sociedade se relacionar com a natureza no mundo ocidental, diferentes das existentes até então. Foi um período em que foi preciso ordenar, medir, comparar e representar os seres em uma ciência geral, um momento em que a linguagem passou a traduzir o mundo. (ARAÚJO, 2001, p.21).

Silver (2003, p.93) atribui a esse período, chamado de Iluminismo, os fundamentos da nossa atual ciência baseada não em revelações ou dogmas e sim na inteligência, na razão e na ciência; ainda que para Barzun (2002, p. 95), razão e natureza sejam palavras tipicamente ocidentais que desafiam uma definição estável. De qualquer modo, o ser humano passaria, então, a "ser arquiteto do seu futuro", baseado nas teorias e ideias de Newton, Bacon ou Galileu, entre outros. Para Urban (1997, p. 390), René Descartes (1596-1650), seria um dos filósofos mais importantes do período, ao descrever o mundo como uma máquina perfeita governada por leis exatas e imutáveis, que poderia ser investigada segundo um método racional, nisso incluindo a natureza. Mas esse tipo de pensamento trazia embutido uma ideia de que tudo poderia ser reduzido à sua natureza física. 
Assim, conforme Araújo (2001, p. 67), Foucault considera que a ciência progrediu não só pela experimentação ou por um novo método, mas por novas "vontades de verdade", universais, ricas e prolíferas, através da divisão do conhecimento científico em instituições como escolas, laboratórios, publicações especializadas, nas quais o cientista e o técnico teriam, a partir de então, um papel extremamente valorizado.

Entretanto, para Barzun (2002, p. 225), a realidade acabou sendo também dividida. O fato científico e a experiência humana deixaram de ser uma única e mesma coisa, contradizendo-se frequentemente. Assim, a única forma de escapar dessa contradição era não ver o homem como parte da natureza. Em um sentido primordial, ele a enfrentava como algo a ser conquistado, como algo bruto, sem consciência.

Grün (1996) mostra que a visão humana da natureza sob o enfoque do método cartesiano acaba ganhando caráter eminentemente antropocêntrico, enxergando a natureza através de um viés utilitarista, algo que já estava presente em doutrinas pós-socráticas, mas principalmente visando o domínio puro e simples. Isso explica porque até o século XVIII valorizava-se mais o mundo natural domesticado ou cultivado do que a natureza propriamente dita. (DIEGUES, 2001, p. 23).

Para Diegues (2001, p. 43), a dicotomia homem-natureza e o enfoque antropocêntrico teriam se agravado com o surgimento da ciência moderna, quando o mundo natural se torna objeto desse conhecimento empírico-racional. Filosoficamente falando, essa ciência tinha por objetivo devolver ao homem o domínio sobre o mundo, perdido com o pecado original. No entanto, para esse autor, com Descartes, extremou-se a separação entre o homem e a natureza, gerando uma desvalorização dessa. Por outro lado, segundo Barzun
(2002, p. 225), a grande vantagem para a ciência de um universo sem propósito ou fim determinado (como na religião), é a imaginação liberta. Aliás, para prosperar, a ciência precisou do incremento da comunicação. Instituições de divulgação científica foram criadas e a experiência dos novos cientistas ensinou-lhes que as grandes descobertas são feitas passo a passo e que críticas e correções mútuas auxiliam a todos. Ao contrário do período obscuro dos alquimistas, a fama, a princípio, não seria negada a quem ajudasse a construir o "edifício da ciência".

Através do texto de Grün (1996) é possível entender os antecedentes epistemológicos do tratamento das questões ambientais e das relações entre sociedade e natureza dentro da ótica cartesiana. Percebe-se que a natureza é ausente, distante, "coisificada" (recursos hídricos, florestais, etc.), ou tem valor negativo (poluição, degradação, impacto). O humanismo cartesiano prega o domínio humano sobre todas as coisas e criaturas e, consequentemente, sua separação da natureza e seu posicionamento acima dessa. De tal modo, todo um corpo de saberes ecologicamente sustentáveis pode ser varrido para o lado se não for científico ou tecnologicamente moderno.

\subsection{A concepção cartesiana de susten- tabilidade}

De acordo com a avaliação de Struminski (2006), no Brasil o discurso cartesiano surge com a vinda de brasileiros que estudaram em escolas portuguesas reformadas pelo Marquês de Pombal, no século XVIII: um momento em que procurava-se, pela via intelectual, substituir a tradição religiosa pela ciência racional e aplicada, pela inteligência e pela razão, com o objetivo final de recuperar a riqueza e a posição de destaque mundial de Portugal, perdidas 
no século XVII. Esses brasileiros estavam, então, sendo treinados para desenvolver a colônia brasileira com bases mais modernas, para usufruto da metrópole.

Durante o Império brasileiro, esses intelectuais usariam o discurso científico para se contrapor àquilo que eles consideravam como usos destrutivos da terra - queimadas, desmatamentos, erosões -, vistos por eles através da lente do conhecimento científico. O discurso cartesiano introduziu, portanto, uma forma elaborada de crítica ambiental que até então não existia no Brasil.

Esse tipo de conhecimento foi incorporado no país nascente e consolidou-se em diversas instituições nacionais e internacionais com as quais os cientistas brasileiros dialogam até hoje. Com isso, o discurso cartesiano mantém-se hoje amplamente disseminado nas instituições científicas e de ensino, nos governos, nas empresas e no terceiro setor (inclusive ambientalista), nas instituições que utilizam a linguagem técnica ou científica sobre temas ambientais.

Com base no discurso científico, podese dizer então que a sustentabilidade será obtida pela aplicação do conhecimento racional a tudo que possa ser submetido a seus métodos. No caso do método cartesiano em particular, será sustentável tudo cuja análise possa ser simplificada e que possa ter seus resultados extrapolados, toda complexidade que possa ser fragmentada e depois reordenada conforme o interesse científico.

O cartesianismo, porém, não é sustentável, pois esse método reducionista não pode ser aplicado a todas as atividades da humanidade, particularmente em situações complexas - ou, quando é aplicado, induz a erros de generalização. Além disso, por seu caráter antropocêntrico, o cartesianismo acaba enxergando a natureza por um viés utilitarista ("coisificação") ou de domínio puro e simples, o que desvaloriza a natureza e gera insustentabilidade, devido aos danos potenciais da ação humana sobre o mundo natural.

O grande paradoxo e entrave para a manutenção de sociedades ambientalmente sustentáveis, com o enfoque cartesiano, é que ele supervaloriza a ciência, em última análise uma das grandes responsáveis pela degradação ambiental do mundo atual, em detrimento de outras formas de pensamento, como o naturalista e o tradicional. Por outro lado, o cartesianismo pode contribuir para a sustentabilidade na medida em que aumente o conhecimento humano sobre a natureza, diminua seu antropocentrismo, introduza métodos interdisciplinares de pesquisa e reduza sua ênfase nos aspectos degradantes da intervenção humana sobre a natureza, ampliando a análise sobre aspectos positivos.

\subsection{O discurso naturalista}

A partir do Renascimento, ao mesmo tempo em que surgiam os modelos de natureza racionalizada comentados no item anterior, surge a concepção de uma natureza intocada através de utopias antiurbanas, que visavam à restauração de uma "natureza perdida".

Urban (1997, p. 390) cita uma frase de Goethe que dá o tom de um nascente movimento naturalista que surgiu nessa época, a chamada Naturphilosofie: "cada criatura é apenas uma gradação padronizada de um grande todo harmonioso". A autora interpreta essa ideia como um esforço de integrar o ser humano à natureza, mas também como uma tentativa de demonstrar a pequenez e o papel desse mesmo ser humano frente à ela. Essa filosofia rejeitava a frieza da lógica, preferindo a intuição e a metafísica, mesmo que obscuras.

Pode-se dizer, então, que o holismo de Goethe seria uma tentativa de criar um 
antídoto para a alegada fragmentação da ciência moderna. Os adeptos da Naturphilosophie tinham empatia com a ênfase que Rousseau dava aos instintos e às sensibilidades do homem e com seu desejo de uma cultura que incluísse as virtudes que ele via em sociedades antigas e primitivas, algo presente até hoje nos movimentos da chamada "Nova Era".

Para Grün (1996), a escola arcaísta que Diegues (2001) chama de romântica, ou naturalista reativa, e Barzun (2002) de primitivista, surgiu então como uma reação ao cartesianismo e ao racionalismo típico do período iluminista. Esse autor define o arcaísmo como antropomórfico, holístico, orgânico, nostálgico, feminista (mãenatureza), "antimodernista", "hipermodernista", "sobrevivencialista" ou mesmo alienado. Paradigmas que, de qualquer ângulo, excluem o ser humano da natureza, o colocam em segundo plano (biocentrismo), ou pregam o fim da civilização atual industrial e urbana como requisito para a obtenção da qualidade de vida.

Por outro lado, a preservação da natureza pode ser descrita como uma apreciação estética e espiritual da vida selvagem. (DIEGUES, 2001, p. 24). Mas esse caráter espiritual pode ser ampliado por aqueles que encaram o naturalismo como uma doutrina filosófica que atribui tudo à natureza como primeiro princípio, nesse caso configurando uma espécie de fundamentalismo natural. Esse mesmo autor comenta que nos Estados Unidos um dos mais importantes desdobramentos desse naturalismo foi a criação do conceito de parque nacional como área selvagem, após a consolidação do capitalismo, o virtual extermínio dos índios, o esgotamento das fronteiras agrícolas e a urbanização acelerada que aquele país sofreu. Para o naturalismo americano do século XIX, a única forma de proteger a natureza era afastá-la do homem, por meio de "ilhas selvagens" (wilderness) onde esse pudesse admirá-la e reverenciá-la. Os parques seriam então essas ilhas, grandes áreas não habitadas, reservadas e colocadas à disposição das populações urbanas para fins de recreação, pois o crescimento populacional, após a Revolução Industrial, teria gerado queda na qualidade de vida e um sentimento antissocial e antiagregativo.

As primeiras áreas naturais protegidas do Brasil surgiram no século $X X$, seguindo o modelo das wilderness norte-americanas, a partir de bases ideológicas, mitos e doutrinas arcaístas urbanas formuladas naquele país, como uma reação ao "culturalismo" - uma visão de base cartesiana que via na natureza imperfeita uma enfermidade do homem, além da necessidade de domesticar o mundo e o homem natural por meio da civilização. Assim, a ideia que se contrapunha a isso era a de que, se a natureza fosse toda transformada, deveriam ser mantidos pedaços do mundo natural em seu estado estético primitivo. (DIEGUES, 2001, p. 13). Por trás disso estava o mito do paraíso terrestre cristão.

Rodman, citado por Diegues (2001, p. 35), afirma que a criação dos parques obedeceu a motivações biocêntricas estéticas, religiosas e culturais, mas não necessariamente naturais (valorização dos processos ecológicos naturais), de populações urbanas (o que também não deixa de ser, paradoxalmente, um antropocentrismo) mostrando que a natureza (ou as populações tradicionais que lá viviam) não foi considerada um valor em si, digno de ser protegido. Também Gomez-Pompa e Kaus, citado pelo mesmo autor, criticam a noção de mundo natural, que reflete um mito e uma utopia urbana a respeito da natureza como terra "intocada", sendo, portanto, uma visão de pessoas que vivem longe do ambiente natural do qual dependem como fonte de matéria-prima. Para esses autores, esses conservacionistas veem o 
valor estético, biológico e ecológico, mas não as populações humanas, seus eventuais efeitos positivos, ou reconhecem o valor econômico de um uso sustentado.

Atualmente, já existe uma base muito mais ampla para a criação de uma unidade de conservação, o que inclui pesquisas científicas, além de consultas públicas. Mesmo assim, a noção naturalista do olhar humano sobre a natureza persiste. Em 2004, numa publicação destinada a ecoturistas, a ONG ambientalista WWF (2004) sugere que esse público seja eminentemente urbano, ao comentar que os ambientes naturais são "locais onde a natureza precisa ser tratada com cuidado e respeito", não sendo possível "realizar trabalhos de limpeza e recuperação da mesma forma como acontece nas cidades" (sic).

\subsubsection{A sustentabilidade na visão naturalista}

Conforme analisa Struminski (2006), o naturalismo surgiu no início do século XIX como uma doutrina que fundamenta a conduta humana na satisfação dos instintos biológicos, no individualismo, no antirracionalismo e no antimaterialismo. Também critica a degradação gerada pela aplicação da doutrina cartesiana ou pelo uso tradicional do mundo natural.

No Brasil, segundo Struminski (2007a), as ideias naturalistas românticas começaram a surgir no início do século XIX, agregadas a um sentimento de ufanismo vinculado à publicação, em 1817, da carta de Pero Vaz de Caminha, que descrevia o Brasil com tintas róseas. Esse ufanismo começou a ser usado como uma estratégia de atração de colonos, pois a terra aparecia sempre copiosa, formosa, fértil, de clima brando e de águas fartas. Seus habitantes (índios) seriam amigáveis, ingênuos e inocentes como os moradores do paraíso terrestre.
É daí que o Romantismo brasileiro, inclusive com patrocínio oficial, partiria, elegendo a natureza copiosa como cenário da unidade nacional e o índio como herói, paradigma da identidade nacional. Seria o índio nobre, idealizado pelo conceito do homem natural rousseauniano, e que vive ainda no imaginário brasileiro e europeu. Essa simbologia alcançaria seu esplendor com o indianismo de Gonçalves Dias e, sobretudo, de José de Alencar. Índios de um passado imaginário, anterior à chegada dos portugueses, de uma história a ser escrita.

Com essa descrição, vemos uma percepção de sustentabilidade vinculada ao passado, a uma natureza intocada ou a uma sociedade primitiva, sem os males modernos. Com isso, devido ao seu biocentrismo, o naturalismo pouco contribui para a sustentabilidade social, havendo mesmo uma rejeição à humanidade ou à sociedade atual (neomalthusianismo), ou quando muito, como vimos, uma visão romântica sobre sociedades antigas.

Por outro lado, parte das ideias naturalistas sobre a sustentabilidade (inclusive sobre a economia) tem influência direta da biologia, sendo sustentável aquilo que é capaz de se manter mais ou menos constante, ou estável (que não varia, ou quando varia, volta ao estado anterior após a variação), por longo período, ou por algo que pode ser substituído por um equivalente. Outra parte costuma considerar a sustentabilidade como um processo ascendente contínuo, no qual concepções mais sofisticadas se sucedem, enquanto outras, menos aptas, desaparecem. A primeira das concepções origina-se da biologia descritiva, a outra, da biologia evolucionista.

No entanto, pode-se concluir que, do ponto de vista da sustentabilidade ambiental, a parcela do naturalismo que busca aplicar o discurso da biologia descritiva pouco contribui para o enfrentamento da 
destruição ambiental, ou, quando muito, tem contribuído para o isolamento e fragmentação de ambientes naturais - algo que ironicamente, a própria Biologia da Conservação refuta atualmente, pois essas áreas florestais não mais se comportam como florestas intactas. (RODRIGUES, 1998).

O discurso naturalista mantém-se hoje em parcelas de instituições científicas e de ensino voltadas para a conservação da natureza, setores governamentais ligados à conservação, empresas que utilizam o marketing ecológico como ferramenta de vendas e no terceiro setor ambientalista, que se utiliza de discursos arcaístas para defender ambientes intocados.

O naturalismo contribui para a sustentabilidade na medida em que nos alerta, com base na Biologia, para a necessidade da manutenção dos ecossistemas, das suas funções ou da evolução ao longo do tempo. Do ponto de vista da sustentabilidade econômica existe uma ênfase em tecnologias limpas e de pequena escala ("verdes"), novos mercados, novas fontes de energia orientadas para recursos renováveis, que podem efetivamente promover mudanças importantes e relevantes à medida que sejam implementadas. Finalmente, e isto também é importante, o naturalismo nos lembra que nem todas as trocas que realizamos com a natureza podem ser mediadas com valores de mercado. O naturalismo promove uma valorização estética e sublime do mundo natural selvagem, o que vem sendo cada vez mais reconhecido como um valor a ser considerado, ainda que subjetivo.

\subsection{O discurso liberal}

O liberalismo surgiu na Inglaterra e na França do século XVII, entre a burguesia europeia, como uma forma de defender o direito natural à liberdade, sustentando que a autoridade devia se limitar a assegurar esse direito aos cidadãos e garantir liberdade de consciência.

Foucault (1997, p. 91) nota que o liberalismo trouxe uma problemática nova: a da "sociedade". É em nome dela que se irá procurar saber por que é necessário que haja um governo, em que situações é possível prescindir dele, quando sua intervenção é inútil ou prejudicial, ou mesmo que fins ele deve ter em relação à sociedade.

Von Mises (1987, p. 7) explica que o liberalismo é racionalista e inteiramente materialista, não se referindo a necessidades espirituais ou metafísicas. Ainda que o liberalismo sofra de uma fixação do desejo de aumento de produção e do bem estar material (a natureza como "capital"), esse autor afirma que quem o considere apenas por esse ângulo demonstra uma compreensão imperfeita desse movimento político, que foi o primeiro a almejar a promoção e bem-estar de todos. De qualquer forma, Touraine $(1995$, p. 228) considera que o pensamento liberal se esforça em aproximar e até mesmo confundir o mundo da natureza e o mundo da ação humana, buscando afastar uma concepção ultrapassada do determinismo que sempre apelou para respostas por demais espiritualistas (românticas).

A partir de 1880 surgiram liberais reformistas, mais preocupados com a justiça social nas comunidades, em vista dos efeitos do industrialismo. (PAIM, 1998, p. 47). Tratava-se de uma reação também às ideias socialistas que "atropelavam" $o$ individualismo liberal e eram tidas pelos liberais como comprometedoras da liberdade e desestimuladoras da responsabilidade individual. Foucault (1997, p. 92) comenta então que o liberalismo passou a se tornar "polimorfo", tanto servia como crítica, como regulador da prática gover- 
namental. Por outro lado, Pádua (2002, p. 107) mostra como um discurso liberal conservador se chocou contra as pretensões de conservação dos recursos naturais que os ilustrados administradores da colônia brasileira tinham.

Conforme Barreto (1982, p. 17), em uma sociedade liberal conservadora, aqueles que têm propriedade são membros integrais da sociedade, "a recompensa de Deus ao homem trabalhador e religioso". A riqueza é condenável eticamente só na medida em que constituir uma tentação para a vadiagem e para o aproveitamento pecaminoso da vida. Os proprietários são, pois, cidadãos de primeira classe, participando da administração do Estado e detendo o poder, mesmo sobre aqueles que discordavam, o que contradiz a ideia atual da democracia.

Com isso, Pádua (2002, p. 107) nota a presença, no século XVIII, de uma ideia ainda em voga nas discussões sobre política ambiental: a de que a privatização dos espaços naturais é o melhor meio para conservar seus recursos, uma tese bem fundamentada na teoria (os proprietários seriam os maiores interessados na conservação, desde que tivessem garantia de posse e liberdade para administrar seus negócios), mas muito pouco demonstrada na prática. Em verdade, geralmente acontece o contrário, como demonstrou Struminski (2007b) em um artigo sobre o Código Florestal criado na Era Vargas.

\subsection{Como o liberalismo entende a sustentabilidade}

Como aponta Struminski (2006), o liberalismo surge no Brasil também com a vinda de brasileiros que estudaram na Europa, durante o conturbado período da Revolução Francesa.

A sustentabilidade social representa tudo para o liberalismo moderno, pois a sociedade fundamenta a vida das pessoas. Essa sustentabilidade era inicialmente baseada nas posses e na liberdade individual. Desse ponto de vista, o liberalismo provou ser insustentável no Brasil, onde uma versão conservadora acabou gerando distorções como a excessiva concentração de terras na mão de poucos proprietários.

O liberalismo prega a sustentabilidade ambiental a partir do mercado. Entretanto, pode-se concluir que dentro do liberalismo conservador brasileiro, quem tinha fatores de produção à sua disposição, na sua propriedade, foi muito pouco cuidadoso ao empregá-los, gerando insustentabilidade ambiental, como desmatamentos, erosões e perda da biodiversidade.

O discurso liberal é amplamente disseminado na sociedade. Aparece em plataforma de governos, é adotado por empresas privadas e pelo mercado e frequenta a sociedade na forma branda do liberalismo social, que defende ações individuais ou de pequenos grupos. Por outro lado, em um ambiente democrático, o liberalismo contribui para a sustentabilidade na medida em que busca suprimir toda a opressão considerada anormal, ilegítima, imoral; valoriza a liberdade, a justiça e a iniciativa social. O liberalismo prega, então, a existência de um governo responsável, não arbitrário, que respeite os cidadãos, o que é favorável à sustentabilidade social.

\subsubsection{O discurso positivista}

Segundo Rodrigues (1982, p. 13), o messianismo político empolgou o pensamento de vários autores no século XIX, como Comte (1798-1857), Michelet (1798-1874), Mazzini (1805-1872) ou mesmo Karl Marx (1818-1883). Esse messianismo os fazia entrever o nascimento de uma doutrina universal (ou até mesmo uma religião, como no caso da igreja positivista) que 
impusesse a organização à sociedade. Era a forma como alguns deles encaravam a profunda crise da sociedade europeia, após a queda ou contestações a antigos regimes monárquicos após a Revolução Francesa. Para Rodrigues (1982, p. 14), esses autores buscavam ideias novas, um sistema que fosse, por natureza, cortante, absoluto e exclusivo.

Explica Rodrigues (1982, p. 18) que, nessa proposta, particular importância tinha o dogma científico, com a primazia da teoria sobre a prática cuja essência só poderia ser compreendida por uma elite intelectual reduzida, que se dedicaria ao estudo das ciências sociais e que estaria incumbida do governo e da direção da sociedade. As massas só teriam uma incumbência com relação à essa elite, aceitar a nova doutrina, como no passado, de forma dogmática. Só os cientistas exerceriam, em matéria teórica, uma autoridade incontestável e possuiriam força moral reconhecida.

Além disso, haveria um dogma religioso, no qual a definitiva revelação seria o progresso, uma noção que, diga-se de passagem, não era privilégio dos positivistas, pois, segundo Barzun (2002, p. 100), já fazia parte das experiências humanas pelo menos desde o século XVI.

Rodrigues (1982, p. 19) considera que os dogmas positivistas (e alguns outros do mesmo período histórico) traziam o nascedouro do autoritarismo moderno, pois, mesmo que ninguém fosse obrigado a crer nos sentimentos de sociabilidade apregoados pela(s) nova(s) religião(ões) ou doutrinas científicas, poderia ser banido do Estado se não acreditasse neles, sendo tachado como antissocial, incapaz de amar as leis, a justiça e de sacrificar sua vida na execução do dever. Ou seja, estaria sujeito a isso qualquer um que não acreditasse em uma visão matizada e não dogmática da sociedade. No fundo, esses projetos "libertadores" e "regeneradores" da socie- dade trariam uma concepção determinista, autoritarista e materialista, muitas vezes nefasta ao próprio homem como se veria nos anos seguintes. Merquior (1998, p. 30), a propósito, lembra que dentro da filosofia jurídica do positivismo o próprio Estado é visto como uma estrutura de normas, um corpo de leis, um conceito lógico útil, uma unidade jurídica e não uma substância real com pessoas reais como no mundo grego antigo.

Assim sendo, para Sevcenko (1999, p. 17), a consagração da ciência positiva como apanágio do progresso no século XIX e início do XX pôs em cena uma nova elite de cientistas, médicos, engenheiros, técnicos administradores, arquitetos e urbanistas.

\subsubsection{A concepção positivista da sustentabilidade}

Struminski (2006), avaliando o discurso positivista, concluiu que ele surge no Brasil em meados do século XIX, sobretudo após a Guerra do Paraguai, em função das demandas por ordem social e progresso que os positivistas acreditavam não serem supridas pelo Império brasileiro, essencialmente liberal conservador.

A sustentabilidade social é representada no positivismo pela ideia da ordem. As dificuldades sociais não são essencialmente políticas, mas, sobretudo, morais. Entretanto, os atos da vida são estreitamente regulados: se reprime o individualismo e a liberdade moral, pois são incompatíveis com a ordem social. Há também um repúdio aos instrumentos de representação popular.

Do ponto de vista da sustentabilidade econômica, o positivismo prega a ideia do progresso como consagração da objetividade da ciência positiva e da tecnologia. Entretanto, como a essência dessa ciência só pode ser compreendida por uma elite 
intelectual, ("autoridade competente"), incumbida do governo "da opinião" e da direção da sociedade, qualquer dúvida com relação à objetividade desse processo leva ao estancamento do progresso e da sustentabilidade econômica.

A sustentabilidade ambiental surge na tentativa de atribuir ao Estado o papel de regulador e ordenador das iniciativas individuais (com regulamentos sobre a propriedade privada) e do território (unidades de conservação, políticas, planos, programas e projetos), com base em pressupostos técnicos, que ampliam o poder de controle, fiscalização e repressão sobre a sociedade, que nem sempre compreende ou aceita isso. Assim, a sustentabilidade ambiental nem sempre ocorre.

Existe ainda a noção de que o ambiente natural pode ser "manejado racionalmente" a partir de instrumentos científicos e tecnológicos. Embora esse tipo de manejo se aplique a várias situações, essa visão esbarra nas dúvidas com relação à objetividade técnica, científica ou da burocracia, frente à imensa e até certo ponto desconhecida diversidade natural, podendo gerar, em casos extremos, degradação ambiental.

O discurso positivista frequenta instituições governamentais que buscam regular a vida do cidadão. As instituições de ensino são fortemente influenciadas por essa doutrina e disseminam o discurso do progresso científico. O direito positivo fundamenta a propriedade pública no Brasil e limita a propriedade privada.

Porém, o positivismo contribui para a sustentabilidade na medida em que aumenta a importância e o interesse pelo bem público e limita os excessos que podem ser gerados pelo liberalismo sem controle, um problema sempre importante na vida brasileira.

\section{ANÁLISE DE PROJETOS APLICADOS NA SERRA DO MAR CONFORME SEUS DISCURSOS, AVALIAÇÃO E RESULTADOS}

Conforme foi visto, os diferentes discursos que regem as relações entre sociedade e natureza ainda estão presentes, mesmo passados séculos desde suas elaborações iniciais e introduções no Brasil. Esses discursos trazem concepções limitadas sobre sustentabilidade. Quando aplicados em projetos práticos, em uma dada área geográfica, essas limitações ficam aparentes, podendo inclusive trazer resultados opostos aos pretendidos, conforme será visto a seguir.

\section{O SISTEMA DE UNIDADES DE CONSERVAÇÃO NA SERRA DO MAR PARANAENSE}

\subsection{Síntese da criação do sistema}

A história da criação de Unidades de Conservação da Natureza na Serra do Mar do Paraná é marcada por altos e baixos, grandes fracassos e algumas vitórias. A partir dos anos 1970, os governos estaduais paranaenses criaram diversas UCs de Proteção Integral na Serra do Mar, que visavam preservar a natureza, com uso indireto dos recursos naturais. Em 1978, foram criados os Parques Estaduais do Marumbi I e II, em 70 mil hectares de Regiões Serranas do litoral e da Região Metropolitana de Curitiba (RMC). Porém, ao fim de cinco anos, prazo em que caducaram os decretos, apenas 480 hectares foram desapropriados e o parque perdeu a validade. Em 1979, o Paraná cria o Parque Estadual das Lauráceas, na fronteira com São Paulo, que com 25 mil hectares segue sendo a UC estadual mais representativa. (JACOBS, 1997).

Após 1980, a legislação federal permitiu a criação de unidades de uso sustentável 
com o objetivo de compatibilizar a conservação da natureza com o uso (privado) de parte dos recursos naturais. (STRUMINSKI, 1996). Em 1984, a área do antigo parque Marumbi I passa a ter o uso do solo regulamentado através de uma nova modalidade de unidade de conservação, a Área Especial de Interesse Turístico (AEIT) do Marumbi (atual APA da Serra do Mar). Para o restante da Região Serrana, a regulamentação ocorreu na forma de um Edital de Tombamento da Serra do Mar, em 376 mil hectares. (STRUMINSKI, 1996). Na prática, todo o ecossistema da Floresta Ombrófila Densa (Floresta Atlântica), com 500 mil hectares, passaria por alguma forma de regulamentação de uso estadual ou federal, o que de certo modo restringiu e garantiu a conservação desta região.

Conforme Struminsky (1996), após 1990 são criadas novamente UCs de Proteção Integral (pequenos parques na Serra do Mar, entre 2 e 4 mil hectares) através de discriminatórias fundiárias - pesquisas em cartórios de imóveis - ao final das quais se descobre a existência de "terras devolutas" que, por não possuírem registro, podem ser "devolvidas" ao Estado (por isso o nome), sem necessidade de indenização. Nesse caso, os novos parques foram criados com áreas consideravelmente mais modestas que a do parque original, mas de forma um pouco mais consolidada - isto é, alguns tem plano de manejo, conselhos gestores ou mesmo ações de manejo. Também pode ser citado o caso da criação de UCs via Medida Compensatória, pela implantação de empreendimentos. Esse é o caso, por exemplo, do Parque Estadual da Serra da Baitaca, criado no papel, que espera sua implementação como compensação pelo impacto da obra do Contorno Leste da BR 116 pelo Departamento Nacional de Infraestrutura de Transportes (DNIT).

Em fevereiro de 1993, o trecho paranaense da Serra do Mar passa a integrar a
Reserva da Biosfera da Mata Atlântica estabelecida pela UNESCO que, apesar de não ser uma UC, significa um reconhecimento internacional do valor dessas regiões como contendo ecossistemas representativos. Parte da Serra do Mar paranaense também foi transformada em parques federais (Superagui, Saint-Hilaire-Lange). Entretanto, os maiores esforços de manejo continuam sendo de instituições estaduais.

\subsection{Avaliação do sistema de UCs na Serra do Mar no Paraná}

O Sistema de Unidades de Conservação da Serra do Mar reflete, obviamente, influências dos discursos da sociedade sobre a natureza (em particular do discurso naturalista), podendo ser considerado a mais persistente resposta governamental para a conservação da natureza. Parte, portanto, de uma estratégia de sustentabilidade ambiental para essa região.

O gerenciamento do território via UCs de uso público estadual de forma direta nessa região - que pode ser estimado em torno de 10 \% segundo Jacobs (1997) e Struminski (2006) - representa um modelo limitado frente ao quase total predomínio da propriedade privada, ainda que todo o solo tenha uso regulamentado e consideravelmente restringido (um pressuposto positivista). A categoria parque é predominante e existe pouca participação de outras categorias de manejo de proteção integral do sistema como as Estações Ecológicas, Reservas Biológicas, ou Florestas Estaduais. Há pouco ou nenhum planejamento visando a aspectos estratégicos importantes para a conservação da natureza. Assim, as UCs tendem a se constituírem como "ilhas", com ambiente natural melhor conservado frente a ambientes rurais ou urbanos vizinhos à Região Metropolitana de Curitiba e ao litoral do Paraná. Isso gera 
pouca conexão com outras áreas naturais fora da Serra do Mar.

O discurso da sustentabilidade ambiental dessas UCs, do ponto de vista do saber cartesiano (seleção de áreas por critérios biológicos), combinado à percepção naturalista (áreas de grande beleza cênica) teve sucesso limitado na região, em função da persistência da visão liberal conservadora de que só aquilo que não tem título ou registro como propriedade privada acaba sendo "devolvido" ao Estado para se criar um parque, mas principalmente diante das próprias limitações do governo estadual em gerenciar, de forma competente, esses territórios.

O sistema no qual estão inseridas essas UCs apresenta contradições. Uma mesma categoria de manejo, como uma Área de Proteção Ambiental (APA), onde o território a ser conservado é normatizado pelo governo estadual, pode refletir um discurso naturalista biocentrista (conservação da natureza) ou utilitarista cartesiano (manutenção de recursos hídricos). Assim os conflitos de uso são inevitáveis.

Conforme visto anteriormente, as unidades de conservação são ainda influenciadas pelo discurso positivista, tendo a ordem como principal pressuposto (ordenamento territorial), já que ela aumenta a capacidade normativa dos órgãos estatais de gerenciamento ambiental através de planos de manejo. Também há a utilização da ciência cartesiana em trabalhos disciplinares (mapeamentos temáticos), ou multidisciplinares (SIGs), visando à proteção, manejo e controle da UC. Isso, no entanto, não necessariamente orienta a sociedade, por separá-la da natureza (visão naturalista) através do zoneamento, que define setores com objetivos e normas, os quais proporcionam meios para que os objetivos da unidade sejam alcançados. Contudo, na prática essas zonas são como a de "amortecimento" (entorno de uma
UC), onde as atividades humanas são sujeitas a restrições para minimizar impactos negativos sobre a unidade.

Esses planos e zoneamentos, muitas vezes de difícil acesso e compreensão, podem se tornar fonte de dificuldades para os moradores de áreas afetadas por UCs, não acostumados ao linguajar técnico. Já para os técnicos que lidam com essas UCs, surgem dificuldades quando os planos são feitos por consultorias externas ao órgão ambiental. Ademais, pode existir ainda sobreposição de áreas (ex.: APAs sobre Tombamento), com conflitos de normas e de esferas de administração.

Com tudo isso, a criação de conselhos consultivos e a eventual parceria com instituições não governamentais, ou mesmo a incorporação de voluntários em programas de manejo (uma estratégia governamental) permitem que se dê um crédito a esse sistema, pois está entre seus objetivos incentivar o uso sustentado dos recursos naturais e a utilização de princípios e práticas de conservação da natureza no desenvolvimento regional. O que significa produzir o maior benefício, em bases sustentáveis, aos seres humanos, buscando-se garantir ainda a sobrevivência de todos os seres vivos.

\section{O PROGRAMA DE PROTEÇÃO DA FLORESTA ATLÂNTICA}

\subsection{Síntese}

O Programa Pró-Atlântica existiu entre 1997 e 2007, a partir da cooperação financeira entre a Alemanha, através do banco Kreditanstalt für Wiederaufbau (KFW), e o Governo do Paraná. Pretendia investir, durante os primeiros cinco anos, US\$ 20 milhões em algumas frentes: capacidade de fiscalização e controle da Secretaria de Estado do Meio Ambiente (SEMA), do Instituto Ambiental do Paraná (IAP) e 
do Batalhão de Polícia Florestal (BPFLO); conservação, preservação e recuperação de 12.000 km² da Floresta Atlântica no Paraná; e buscar alternativas de desenvolvimento sustentado, que compatibilizassem o uso do meio ambiente com o desenvolvimento socioeconômico e cultural, proporcionando opções de renda às comunidades pobres na área de abrangência do programa. ${ }^{1}$

Para esse objetivo, pretendia-se articular alianças sólidas com as prefeituras e a sociedade das áreas de abrangência do programa, bem como construir alternativas econômicas e ecologicamente sustentáveis para a população do entorno de UCs na forma de projetos pilotos de desenvolvimento sustentável.

O Pró-Atlântica monitoraria sua intervenção na Floresta Atlântica com quatro indicadores: cobertura vegetal natural; manutenção da integridade dos ecossistemas (fauna e flora); qualidade da água; e qualidade do ar. No intuito de criar bases para esse monitoramento, o Pró-Atlântica realizou levantamentos temáticos da região da Floresta Atlântica através de imagens de satélite e cartas digitais. Foram realizados mapeamentos de vegetação, mineração e cartografia e produzidas cartas temáticas.

O programa elaboraria e implementaria planos de manejo de Unidades de Conservação e restauraria o caminho histórico do Itupava, um grande sítio arqueológico do século XVIII que atravessa a serra. Até 2002, a APA da Serra do Mar teria seu conselho deliberativo formado, com representantes das comunidades locais, prefeituras, instituições governamentais e não governamentais, com o objetivo de participar do gerenciamento das unidades.

A título de educação ambiental, o programa editou a cartilha para procedimentos ambiental-

${ }^{1}$ Disponível em: <http://www.meioambiente.pr.gov.br/ modules $/$ conteudo $/$ conteudo.php? conteudo $=254>$. Acesso em: 30 jul. 2010 mente corretos em florestas e a cartilha sobre a Lei de crimes ambientais, descrevendo 14 infrações contra o meio ambiente. Entre as ações previstas estavam também a reforma de postos de vigilância e escritórios do BPFLO e do IAP, treinamento de fiscais e policiais, elaboração de normas para UCs e formulação de planos, além da informatização de infrações ambientais.

\subsection{Avaliação do programa}

Como este programa possuía financiamento para um prazo extenso, sua sustentabilidade econômica estava previamente garantida por esses recursos (banco alemão KFW). Já para atingir a sustentabilidade ambiental, o Pró-Atlântica usou o discurso do intervencionismo estatal com base em critérios científicos, centrando-se no pressuposto positivista da ordem. Isso se expressava pela intenção de aumentar a capacidade normativa, de fiscalização e repressão dos órgãos estatais ambientais. Normativamente, isso se dá na forma da elaboração de planos de manejo de UCs. Mesmo os trabalhos de educação ambiental do programa apresentam esse enfoque: são compilações de leis ambientais, de caráter policialesco, onde o cidadão (sociedade) invariavelmente tem postura negativa e, mesmo assim, a vinculação do crime com a natureza nem sempre é clara. Por exemplo, a pichação de muros, problema tipicamente urbano, é apresentada como um crime em uma pretensiosa cartilha sobre a Floresta Atlântica. Note-se que esse procedimento ocorre apenas poucos anos após o término de uma longa ditadura militar no país.

Em 2001, os projetos-piloto que pretendiam construir alternativas econômicas e ecologicamente sustentáveis para a população do entorno das UCs foram substituídos por um único projeto na área do 
palmito. O conselho deliberativo APA da Serra do Mar (antiga AEIT do Marumbi) não foi implantado até o momento.

$\mathrm{Na}$ ausência de um diálogo efetivo com a sociedade, o programa utilizou como recurso para sua legitimação a ciência cartesiana, na forma de trabalhos disciplinares (mapeamentos temáticos), ou multidisciplinares (planos de manejo). Trabalhos importantes, obviamente, mas que não escondem a visão fortemente biocentrista do programa. A sociedade externa à Floresta Atlântica foi vista como promotora de sérios danos ambientais, como: desmatamentos; caça; extração de palmito; mineração; agropecuária; queimadas; descargas de lixo e esgoto; consumo de recursos e expansão urbana, ainda que a região onde o programa atuasse fosse pouco urbanizada ou ocupada. O distanciamento da sociedade pode explicar a demora, fracasso ou simples abandono de projetos do programa. Constatou-se que o esforço de treinamento de algumas centenas de profissionais/fiscais ou policiais, ou mesmo a execução de projetos bem intencionados, como o do restauro do Caminho Histórico do Itupava, tende a diluir-se diante da indiferença da população (STRUMINSKI, 2007) ou do tamanho da área a ser fiscalizada $\left(12.000 \mathrm{~km}^{2}\right)$. Por esses diversos motivos, o programa não pode ser considerado sustentável socialmente.

Quando finalmente implantou projetos, o Pró-Atlântica revelou-se fonte de danos à natureza que pretendia proteger, apresentando indicadores de insustentabilidade ambiental, como a destruição de ambientes onde ocorrem espécies endêmicas (impactos da implantação de um sistema de radiocomunicação em floresta de altitude), bem como de patrimônio arqueológico, como danos ao citado Caminho do Itupava (STRUMINSKI, 2007). Não houve sinais de que os indicadores que o programa pretendia usar tenham sido monitorados.

\section{O PROGRAMA ADOTE UMA MONTANHA}

\subsection{Síntese}

Lançado em 2002, durante o Ano Internacional das Montanhas, o Programa Adote uma Montanha tem âmbito nacional e, no caso paranaense, desenvolve-se em porções da Serra do Mar. As instituições de montanhismo, de origem urbana, atuam em parcerias, sendo o programa coordenado regionalmente pela Federação Paranaense de Montanhismo. (STRUMINSKI, 2006).

O programa se justifica, conforme afirmam Ribeiro, Lorenzetto e Rodrigues (2004), pelo fato de que, em diversas iniciativas, os montanhistas mostraram-se como efetivos parceiros da gestão de áreas naturais, principalmente no que se refere ao manejo dessas áreas ou mesmo à criação de Unidades de Conservação.

A adoção a que se refere o programa consiste em realizar várias atividades no decorrer do ano, algumas bastante simples, com o objetivo de auxiliar na proteção e manutenção dos ambientes de montanha. Algumas das atividades sugeridas pela coordenação nacional do Adote (Federação de Montanhismo de São Paulo) para os grupos participantes são: limpeza de trilhas; contenção de focos de erosão; organização e colaboração em campanhas de conscientização dos visitantes, principalmente em épocas de maior afluxo; desenvolvimento, organização e implementação de um sistema mínimo de sinalização para evitar impactos indesejados ao longo de trilhas; realização de cursos de interesse associados ao programa (ex.: combate a incêndios em montanha, resgate a acidentados); sensibilização e mobilização das populações locais.

A metodologia de trabalho do programa prevê a realização prévia de um levanta- 
mento das características e problemas da área escolhida com o objetivo de coletar dados e informações que permitam o delineamento de um plano de ação. Em seguida é prevista a elaboração de um plano de ação anual, com os seguintes itens: descrição detalhada da área, dos objetivos específicos e das ações propostas; cronograma de atividades; previsão de equipes de trabalho; previsão de materiais e de recursos necessários; e, finalmente, previsão de um orçamento. Esse plano é executado em parcerias, sendo os trabalhos realizados em mutirões organizados por voluntários, em ambientes inóspitos e de difícil acesso, nos quais a prática e a experiência dos participantes, mais do que conhecimentos científicos, são determinantes para o sucesso do trabalho. Cada organização deve entrar previamente em contato com o proprietário das terras ou responsável pela unidade de conservação onde pretende atuar e obter a permissão para desenvolver as atividades da campanha.

Além desses aspectos organizacionais, o programa fundamenta suas ações na chamada "ética de mínimo impacto", que, conforme Kunreuther (2005), possui princípios que as pessoas adotam conforme seus valores e seu comprometimento com a conservação do ambiente natural. Fundamentada também na capacidade de autorregulamentação dos excursionistas, essa ética surgiu da constatação da existência de poluição e de destruição de áreas naturais por parte dos excursionistas que as frequentam. ${ }^{2}$

\subsection{Avaliação do programa}

A análise deste programa mostra que sua visão da natureza concilia princípios biocentristas (ética naturalista) com

${ }^{2}$ Texto disponível em: <www.pegaleve.org.br>. Acesso em: 30 jul. 2010 antropocentristas (mínimo impacto). A ciência cartesiana é usada de forma muito limitada, em trabalhos disciplinares (eventuais mapeamentos das áreas onde serão realizadas intervenções). A sociedade é vista, no geral, como promotora de danos ambientais como poluição e destruição de áreas naturais, entretanto, os trabalhos de educação ambiental do programa apresentam o enfoque da mudança de valores individuais. Por outro lado, o programa procura favorecer a conservação da natureza através do voluntarismo, como o estímulo aos mutirões.

Este programa fundamenta seu discurso sobre a sustentabilidade social e ambiental com base nos seguintes princípios:

- Uma mistura entre uma ética naturalista "verde" e humanista cartesiana, que preconiza o uso de tecnologias limpas, o uso de recursos renováveis, a mudança de valores individuais e aspectos como solidariedade, cooperação, voluntarismo e fortalecimento de relações entre grupos e pessoas, estendendo esses princípios a entidades naturais como animais, plantas, rios, montanhas, etc.

- A utilização limitada de conhecimentos provenientes da ciência cartesiana.

- A valorização de iniciativas individuais e de grupos esclarecidos para resolver problemas, com participação limitada de instituições governamentais, dentro dos princípios do liberalismo social.

Uma vez que é realizado por uma comunidade limitada de praticantes de excursionismo/montanhismo - ou seja, com foco voltado mais para os visitantes de áreas naturais do que para os moradores dessas mesmas áreas -, o Adote mantém um diálogo apenas limitado com a sociedade, através principalmente de uma lista aberta de discussões na internet e da participação em mutirões. Ele procura legitimar-se 
frente à sociedade por meio da construção da cidadania proveniente de práticas democráticas, dentro do chamado "diálogo de saberes" (LEFF, 2000). Esse diálogo se dá entre os próprios grupos participantes e entre os detentores de saberes populares e científicos que eventualmente participam do programa. O programa fundamenta-se, portanto, no princípio da construção da autonomia, que deriva da práxis desenvolvida em campo por esses grupos. Ao agir indiferentemente, em áreas públicas ou privadas, o programa sinaliza com uma valorização dos direitos coletivos, ampliando sua sustentabilidade social.

Por outro lado, ele busca a sustentabilidade ambiental mediante o uso e gerenciamento responsável (conservacionista) dos recursos naturais. Nesse gerenciamento, o programa busca produzir ganhos ambientais (por exemplo, melhoria da qualidade da vegetação ou da água) nas áreas abrangidas. Pode-se concluir, portanto, que a proposta de sustentabilidade deste programa é condizente com seus objetivos de proteção e manutenção dos ambientes de montanha.

O programa depende de doações de materiais e de transporte de empresas particulares ou de instituições governamentais para suas atividades. A mão de obra é voluntária. Como não tem objetivos econômicos (fraca sustentabilidade econômica), percebe-se que uma das suas dificuldades é incorporar mão de obra para manter a continuidade dos trabalhos. Há carência de técnicos qualificados para coordenar atividades em áreas que exigem grande desgaste físico e possuem alta diversidade biológica e fragilidade ambiental, havendo dificuldade também na valoração dos seus serviços junto à sociedade.

Um dos resultados obtidos no programa é o de que a educação ambiental é trabalhada a partir de questões cotidianas e comuns à população. Ele também re- duz a dicotomia urbano/rural. Segundo a coordenação do Adote, engajando-se no programa o participante consciente tem a oportunidade de mostrar um bom exemplo de cidadania para o restante da sociedade.

\section{PROGRAMAS DE SUSTENTA- BILIDADE NA SERRA DO MAR, ALGUMAS CONCLUSÕES}

Neste estudo optou-se por uma avaliação de projetos com base não em uma tábua de resultados, com metas ou objetivos cumpridos ou não de cada um deles. Obviamente, esses resultados são importantes, mas podem mascarar intenções ocultas que uma avaliação dos seus discursos revela. Assim, essa é uma metodologia que nos leva a fazer uma reflexão mais aprofundada a respeito daquilo que os projetos realmente pretendem nos dizer.

Uma conclusão geral a respeito desta pequena amostragem dos programas ou projetos aplicados na região recentemente é que nenhum deles, isoladamente, atinge os requisitos necessários para que possam ser considerados modelos de sustentabilidade, seja do ponto de vista social, econômico ou ambiental. Entretanto, deve-se observar que cada um dos trabalhos avaliados contribui em algum aspecto para que a sustentabilidade se consolide como um novo discurso.

Propositadamente, foram escolhidos aqui programas em diferentes escalas de ação, pois o que importou foi a análise de seus discursos e suas concepções de sustentabilidade, sendo secundários até mesmo seus resultados. Enquanto um projeto é milionário, em outro a contribuição do voluntarismo é determinante. Um terceiro depende basicamente da capacidade de articulação de técnicos do Estado. Porém, percebeu-se que, quanto menor o diálogo 
de um projeto com os demais setores da sociedade, menos sustentável ele é, não importando a quantidade de recursos de que disponha.

Essa conclusão é particularmente verdadeira no caso do Programa de Proteção à Floresta Atlântica. Tratou-se de um programa estatal com fortes pressupostos biocentristas e positivistas que atuou na área mais bem conservada do Paraná, a Serra do Mar. O programa teve por objetivos a fiscalização e repressão a crimes ambientais. Apesar de milionário e do nome atraente, tornou-se tão isolado que produziu trabalhos de pouca repercussão social, pouco contribuindo para a conservação da floresta nas próprias unidades de conservação do Estado, onde sua atuação foi mais formal do que efetiva. Nos casos em que sua atuação foi mais direta, chegou a ocasionar, contraditoriamente, danos ambientais e desperdício de recursos públicos. Pode-se concluir que o Pró-Atlântica representa, assim, o menos sustentável dos trabalhos aqui estudados.

Para que esse programa pudesse se tornar sustentável, ou no mínimo menos estranho à sociedade, seria recomendável que tivesse destinado parte de suas vultosas somas à realização de aberturas para a sociedade, apoiando projetos, permitindo auditorias não governamentais, fomentando e mantendo parcerias e diálogos permanentes na área em que atuou - atitudes que supostamente facilitariam a tarefa de conservar a natureza da área de abrangência do programa.

O outro programa estatal está relacionado à conservação da natureza em Unidades de Conservação. As UCs de proteção integral materializaram um discurso crítico sobre a degradação gerada pela civilização. Representam um recorte naturalista em um mundo (ocidental) profundamente cartesiano. Inclusive, em casos extremos, alegava-se que "ilhas" de vegetação natu- ral seriam as únicas formas de proteger a natureza da sanha destruidora do homem. Assim, as Unidades de Conservação têm em sua gênese a negação da humanidade. Não por acaso costumam gerar situações negativas na relação sociedade e natureza. É um senso comum de que as UCs envolvem expropriação de áreas privadas e exclusão de populações (no caso de desapropriações de áreas) ou o "impedimento" ao desenvolvimento.

Muito embora o papel deste tipo de UC seja amplo, compreendendo aspectos sociais e econômicos, no caso da Serra do Mar, este recorte naturalista em UCs de Proteção Integral é realmente muito pequeno. Representa algo em torno de 10 $\%$ da área total da região. Esse número permite concluir que a estratégia aplica$\mathrm{da}$, na forma isolada como foi conduzida pelo Estado no passado, durante décadas a fio, pouco contribuiu para a sustentabilidade da região. Entretanto, ao contrário do Pró-Atlântica, essas UCs integram um sistema de áreas públicas e privadas, onde a possibilidade de diálogo com a sociedade aumenta. Tanto que a abrangência na região com UCs de uso sustentável (onde se mantém áreas privadas) é de praticamente toda a região. Assim, apesar da aparência naturalista, esse sistema tem um discurso majoritariamente cartesiano, no qual a ideia da natureza selvagem é uma exceção (UCs de proteção integral), uma concessão mesmo, quando calha de uma paisagem paradisíaca qualquer cair dentro de uma terra devoluta transformada em parque.

Em algumas das UCs de uso sustentável, a finalidade é utilitarista (criação e manutenção de represas de abastecimento de água e de energia), existindo a incômoda contradição da destruição da natureza para fins públicos dentro de uma UC. Porém, existe também uma propensão (praticamente uma obrigação legal) para a gestão compartilhada das áreas. De modo geral, 
a possibilidade da sustentabilidade como um todo aumenta nesse sistema em função de seus objetivos amplos.

Atualmente, ainda há mínima participação das populações locais no planejamento e manejo das UCs, o que poderia garantir inclusive a melhoria da qualidade de vida das mesmas e mais sustentabilidade. $\mathrm{Na}$ prática, o Estado ainda cultiva vícios positivistas e mantém distância e desconfiança com relação à sociedade. É recomendável, assim, que as câmaras técnicas de APAs ou UCs evoluam para câmaras participativas (ou conselhos gestores), inclusive porque a legislação prevê a participação da sociedade nesse sentido. Por outro lado, a realidade de vastas áreas gerenciadas por poucos técnicos, que de forma abnegada conseguem garantir um nível razoável de conservação (e indiretamente contribuir para sua sustentabilidade), é algo significativo e não deveria ser desprezado. É recomendável que investimentos sejam feitos para aperfeiçoar e aumentar o número de técnicos e apoiar as iniciativas da sociedade pela sustentabilidade destas UCs.

Pode-se concluir que, apesar das críticas que o Sistema de UC possa receber, suas virtudes são maiores que os defeitos e as chances de contribuir para a sustentabilidade em sentido amplo, são, portanto, realmente consideráveis.

O programa Adote Uma Montanha, apesar de restrito no tocante à intervenção no terreno (a área abrangida limita-se a trilhas e locais diretamente usados por montanhistas ou excursionistas, ainda que em grande número e em diversas regiões), possui práticas democráticas indicadoras da sustentabilidade no sentido amplo. Ambientalmente, há o uso e gerenciamento responsável (conservacionista) dos recursos naturais. Existe certo "diálogo de saberes" entre os grupos participantes urbanos e os detentores de saberes populares e científicos - embora o foco para as populações locais seja mínimo. $\mathrm{O}$ programa fundamenta-se na construção da autonomia derivada de uma prática desenvolvida em campo. Valorizam-se também os direitos coletivos, ampliando sua sustentabilidade social, e existe ainda algum apoio econômico de empresas ou do Estado.

Para difundir esses aspectos sustentáveis dos seus serviços junto à sociedade, é recomendável que ele amplie sua base de divulgação para um público mais amplo, de modo a valorizar suas contribuições para a construção da cidadania. Por outro lado, mesmo modesto, limitado tecnicamente e baseado no voluntarismo, o programa trabalha em áreas como UCs do Estado ou sob a influência direta de programas onerosos (como o Pró-Atlântica), ou seja, nas áreas com cobertura vegetal muito significativa (em quantidade e qualidade). Dessa forma, é possivelmente o principal crítico potencial ao manejo das UCs onde atua, sendo recomendável que ele incorpore essa crítica, de forma a contribuir para reduzir os aspectos negativos demonstrados por projetos governamentais ou aumentar a sustentabilidade dos mesmos.

É recomendável também que o projeto busque ampliar sua sustentabilidade econômica, trazendo recursos, incorporando mão de obra local para manter a continuidade dos trabalhos e atraindo profissionais para coordenar atividades em áreas que exijam conhecimento mais técnico - inclusive para que possa efetuar a crítica mais qualificada supracitada.

\section{CONSIDERAÇÕES FINAIS}

Apesar da avaliação em alguns casos até mesmo decepcionante de alguns projetos, a lógica da sustentabilidade observada neles sugere que alcançamos, no momento, a sustentabilidade que a sociedade - com 
seus diferentes atores, projetos, etc. - considera aceitável. A sustentabilidade existe acima de tudo como um processo, não necessariamente linear, mas dialógico ou dialético e contínuo, de aperfeiçoamento das relações sociais e das relações entre sociedade e natureza, que vem sendo modificado e aperfeiçoado de modo cada vez mais acelerado.

Pode-se concluir, portanto, que a sustentabilidade na Serra do Mar é, sobretudo, complexa, não se satisfazendo com discursos simples e reducionistas. Por essa razão mesma foram encontrados programas nos quais convivem diferentes discursos, sendo que um discurso dominante pode se apropriar dos demais, transformando os discursos dominados de acordo com os interesses do principal.

Entre as recomendações para a continuação desse processo de sustentabilidade, está o da reflexão sobre os aspectos positivos das doutrinas que influenciam o pensamento e as relações entre sociedade e natureza na região. Assim, seria bastante recomendável que, em projetos futuros, houvesse maior preocupação com a valorização dos conhecimentos tradicionais; o respeito aos valores naturalistas (que não possam ser valorados do ponto de vista comercial); um cuidado com os princípios biológicos da conservação; uma aplicação (interdisciplinar) do conhecimento científico; o respeito à democracia, ao diálogo e à liberdade de opiniões; e a aplicação sensata do poder do Estado em prol dos direitos coletivos. Uma vez que consigamos produzir projetos com esse grau de equilíbrio, estaremos avançando no processo de sustentabilidade.

\section{REFERENNCIAS}

ARAÚJO, I. L. Foucault e a crítica do sujeito. Curitiba: Editora da UFPR, 2001.

BARRETO, V. Primórdios do liberalismo. O liberalismo e representação política: o período imperial. In: Curso de introdução ao pensamento político brasileiro. Brasília: Editora Universidade de Brasília, unidades I e II, p. 11-107, 1982.

BARZUN, J. Da alvorada à decadência, a história da cultura ocidental de $\mathbf{1 5 0 0}$ aos nossos dias. Rio de Janeiro: Campus, 2002.

DIEGUES, A. C. O mito moderno da natureza intocada. São Paulo: Hucitec, 2001.

FOUCAULT, M. Microfísica do poder. Rio de Janeiro: Edições Graal, 2004.

. Resumo dos cursos do Collège de France (1970-1982). Rio de Janeiro: Jorge Zahar Editor, 1997.

GRÜN, M. Ética e educação ambiental. Campinas: Editora Papirus, 1996.

JACOBS, G. Unidades de Conservação no Estado do Paraná: reflexões sob um contexto históricoambiental. Congresso Brasileiro de Unidades de Conservação. Anais... Curitiba: IAP-UNILIVRE, v. 2, p. 68-80, 1997.

LEFF, E. Complexidade, interdisciplinaridade e saber ambiental. In: PHILIPPI JR., A. Interdisciplinaridade em ciências ambientais. São Paulo: Signus, p. 14-22, 2000.

KUNREUTHER, F. Princípios gerais de conduta para atividades ao ar livre. Guia do aventureiro consciente, São Paulo, n. 1, p. 6-7, 2005.

MERQUIOR, J. G. As reinvindicações do liberalismo social. In: O liberalismo social, uma visão histórica. São Paulo: Massao Ohno Editor, p. 9-44, 1998.

PÁDUA, J. A. Um sopro de destruição, pensamento político e crítica ambiental no Brasil escravista (1786-1888). Rio de Janeiro: Jorge Zahar Editor, 2002. 318 p.

PAIM, A. O liberalismo social. In: MERQUIOR, J. G. O liberalismo social, uma visão histórica. São Paulo: Massao Ohno Editor, p. 45-64, 1998.

RIBEIRO, K. T.; LORENZETTO, A.; RODRIGUES, C. Bases para o manejo de escaladas em unidades de conservação. In: CONGRESSO BRASILEIRO DE UNIDADES DE CONSERVAÇÃO, 4., 2004, Curitiba. Anais... Curitiba: FBPN/REDE Pró UCs, p. 335-345, 2004.

RODRIGUES, E. Efeito de bordas em fragmentos de floresta. Cadernos da Biodiversidade. Curitiba: IAP, v. 1, n. 2, p. 1-6, dezembro 1998. . 
RODRIGUES, R. V. A ditadura republicana segundo o Apostolado Positivista. In: DUVERGER, M.; GUIMARAES, Aquiles Côrtes; PAIM, Antônio. Curso de Introdução ao pensamento político brasileiro. Brasília: Editora Universidade de Brasília, unidades V e VI, p. 11-76, 1982.

SEVCENKO, N. O prelúdio republicano, astúcias da ordem e ilusões do progresso. In: NOVAIS, F. A. História da vida privada no Brasil. São Paulo: Companhia das Letras, v. 3, p. 7-48, 1999.

SILVER, B. A escalada da ciência. Florianópolis: Editora da UFSC, 2003.

STRUMINSKI, E. A política ambiental na era Vargas. Disponível em: <http:/ / www.cienciahoje.pt/ index.php?oid=22081\&op=all\#cont $>$. Acesso em: 06 mar. 2007.

Dossiê Baitaca. Curitiba: Associação Caiguava de Pesquisas/Federação Paranaense de Montanhismo, 2007a.

D. Pedro II adoptou ou romantismo naturalista para consolidar o Império do Brasil. Disponível em: <http://www.cienciahoje.pt/ index.php?oid $=17272 \& o p=a l l \#$ cont $>$. Acesso em: 01 abr. 2007b.

Os discursos sobre a sustentabilidade, no Brasil e na região Metropolitana de Curitiba, de 1500 aos dias atuais. Curitiba: Tese (Doutorado em Meio Ambiente e Desenvolvimento), Universidade Federal do Paraná, 2006. 218 p.

Parque Estadual Pico do Marumbi, caracterização ambiental e delimitação de áreas de risco. Curitiba: Dissertação (Mestrado em Engenharia Florestal), Setor de Ciências Agrárias, Universidade Federal do Paraná, 1996. 112 p.

TOURAINE, A. Crítica da modernidade. 3. ed. Petrópolis: Vozes, 1995.

URBAN, T. Do fogo de Prometeu ao temor do $\mathrm{CO}_{2}$ : a longa história da exploração da natureza pela humanidade. In: Congresso Brasileiro de Unidades de Conservação. 1997, Curitiba. Anais. Curitiba: UNILIVRE, REDE PROUC, IAP, p. 388-402, 1997.

VON MISES, L. Liberalismo segundo a tradição clássica. Rio de Janeiro: José Olympio Editora, 1987. $200 \mathrm{p}$.

Recebido em 24/08/10

Aceito para publicação em 03/12/10 


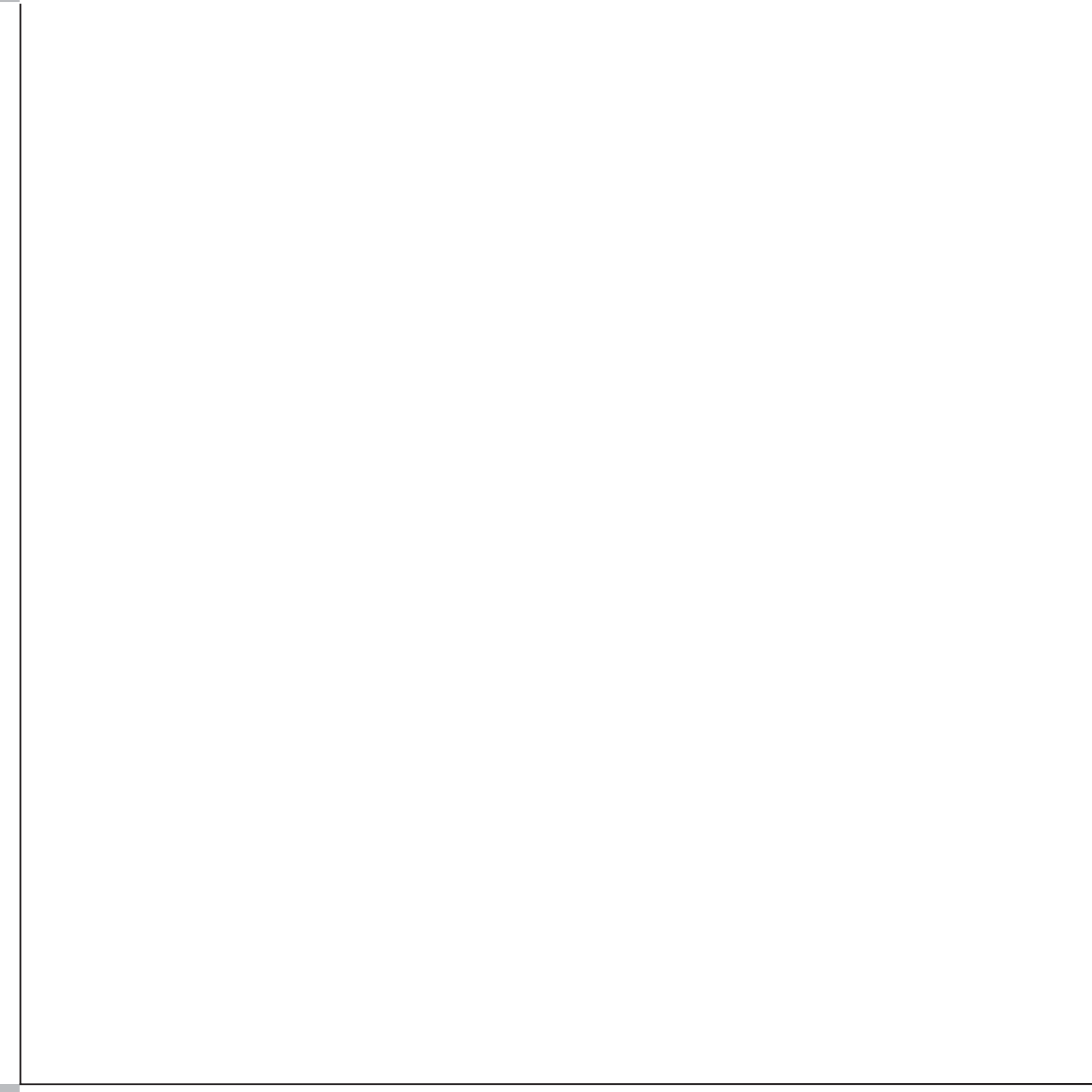

